\title{
Authors' response to the Letter to the Editor regarding: Preventive home therapy for symptomatic patients affected by COVID-19 and followed by teleconsultations
}

\author{
Gennaro D'Amato, ${ }^{1}$ Luca Acanfora, ${ }^{2}$ Lucrezia Delli Paoli, ${ }^{3}$ Maria D'Amato ${ }^{4}$ \\ ${ }^{1}$ Division of Respiratory and Allergic Diseases, Department of Chest Diseases, High Specialty “A. Cardarelli” Hospital, \\ Naples \\ ${ }^{2}$ Managing Director of the Covid-19 nasopharyngeal testing project, for the cooperation agreement between High \\ Specialization in Infectious Diseases "Cotugno Hospital” and "Sovereign Military of Malta" in Naples, Federico II \\ University of Naples \\ ${ }^{3}$ Department of Cardiology and Cardiac Surgery, "San Michele" Hospital, Maddaloni \\ ${ }^{4}$ First Division of Pneumology, “V. Monaldi” High Specialty Hospital and Federico II University of Naples, Italy
}

Correspondence: Prof. Gennaro D'Amato, Division of Respiratory and Allergic Diseases, High Speciality Hospital “A. Cardarelli", Naples; Medical School and School of Specialization in Respiratory Diseases of University of Naples "Federico II”, Rione Sirignano 10, 80121 Napoli, Italy. E-mail: gdamatomail@gmail.com 


\section{Dear Editor,}

We have carefully read the comments by Adiletta and colleagues [1] but we disagree. In our letter [2] we do not suggest therapy at home of COVID-19 in asymptomatic patients but, in our opinion, it is important to help symptomatic patients, also paucisymptomatic ones, since the SARS-CoV-2 can induce ex abrupto a deterioration of symptoms with a cytokine storm [3]. It is well known there are no early signs that could indicate which patient's respiratory symptoms can worsen up to severe acute respiratory failure and hospitalization, so there was the need to help COVID-19 patients in a treatment at home, reducing the frequency of hospitalization $[2,4]$. In our letter [2] we collected our experience and of general practitioners with the need to prevent or delay the arrival of COVID-19 patients in at hospitals and at emergency room [2-4].

As expressed in our letter [2] oral corticosteroids (OCS) are used at anti-inflammatory and not immunosuppressive dosage to reduce symptoms in symptomatic COVID-19 patients [2]. These drugs are frequently used in the therapy of COVID-19 patients with different degrees of disease severity [5-10]. Regarding the role of low molecular weight (LMWH) heparin in SARS-CoV-2 infection, it plays an important role and it is widely used in the prevention and treatment of the thromboembolic complications of COVID-19 [11-13].

However, it was necessary to find a therapeutical approach better than the AIFA protocol [14] that suggests using only paracetamol, which in our experience is not able to reduce the pulmonary COVID-19 pathology.

As published in our letter [2] in Multidisciplinary Respiratory Medicine, we proposed the use of oral corticosteroids and LMWH useful in the treatment of COVID-19 and on this topic there are now several publications, including the protocol of the Italian Society of Pneumology (AIPO) [11], in which OCS and enoxaparin are suggested for the treatment of COVID-19 after 72 hours from the start of COVID-19 symptoms (in our experience after 3-4 days) [2].

We are aware that our therapeutic approach is not a clinical study and there is no control group, but we felt it was important to publish our experience.

Moreover, an Italian Administrative Court (TAR) [15], on March $4^{\text {th }}, 2021$ issued a legal ruling authorizing the clinical physicians to use the drugs they consider useful for the treatment of COVID-19 according to science and conscience, without obligation to follow the suggestion of AIFA protocol.

After the negative result of molecular nasopharyngeal test, patients were invited for a thoracic computerized tomography and laboratory evaluation of d-dimer (following cut-off for the continuous of treatment with LMWH) and other data of inflammation to show and to treat eventual post COVID-19 pulmonary interstitial involvement.

\section{References}

1. Adiletta G, Baglioni S, Bettoncelli G, Bracciale P, Cazzola M, Clini EM, et al. Comments on "Preventive home therapy for symptomatic patients affected by COVID-19 and followed by teleconsultations" by D'Amato et al. Multidiscip Respir Med 2021;16:757.

2. D'Amato G, Acanfora L, Delli Paoli L, D'Amato M. Preventive home therapy for symptomatic patients affected by COVID-19 and followed by teleconsultations. Multidisc Respir Med 2021;16:748.

3. Onder G, Rezza G, Brusaferro S. Case-fatality rate and characteristics of patients dying in relation to COVID-19 in Italy. JAMA 2020;323:1775-6.

4. La gestione della malattia Covid-19. Documento di indirizzo AIPO (Associazione Italiana Pneumologi Ospedalieri) - ITS (Italian Thoracic Society). Edizioni AIPO; 2020.

5. Fu HY, Luo Y, Gao JP, Wang L, Li HJ, Li X, et al. Effects of short-term low-dose glucocorticoids for patients with mild COVID-19. Biomed Res Int 2020;2020:2854186.

6. Almas T, Ehtesham M, Khan AW, Khedro T, Hussain S, Kaneez M, et al. Safety and efficacy of low-dose corticosteroids in patients with non-severe Coronavirus disease 2019: A retrospective cohort study. Cureus 2021;13:e12544.

7. Liu F, Ji C, Luo J, Wu W, Zhang J, Zhong Z, Lankford S, et al. Clinical characteristics and corticosteroids application of different clinical types in patients with corona virus disease 2019. Sci Rep 2020;10:13689.

8. Myall KJ, Mukherjee B, Castanheira AM, Lam JL, Benedetti G, Mak SM, et al. Persistent post-COVID-19 inflammatory interstitial lung disease: an observational study of corticosteroid treatment. Ann Am Thorac Soc 2021. Online ahead of print.

9. Zhagn S, Li D, Chen H, Zheng D, Zhou Y, Chen B, et al. [Dynamic inflammatory response in a critically ill COVID-19 patient treated with corticosteroids].[Article in Chinese]. Zhejiang Da Xue Xue Bao Yi Xue Ban 2020;49:220-6.

10. Almas T, Hussain S, Haadi A, Ehtesham M, Hassan A, Khan AW, et al. When to call it off: Defining the role of low-dose corticosteroids in thwarting the progression of non-severe COVID-19. Ann Med Surg (Lond) 2021;62:236-8.

11. Drago F, Gozzo L, Li L, Stella A, Cosmi B. Use of enoxaparin to counteract COVID-19 infection and reduce thromboembolic venous complications: A review of the current evidence. Front Pharmacol 2020;11:579886.

12. Hao C, Xu H, Yu L, Zhang L. Heparin: an essential drug for modern medicine. Prog Mol Biol Transl Sci 2019:163:1-19.

13. Hippensteel JA, LaRiviere WB, Colbert JF, Langouet-Astrié, CJ, Schmidt EP. Heparin as a therapy for COVID-19: current evidence and future possibilities. Am J Physiol Lung Cell Mol Physiol 2020:319:L211-7.

14. Italian Medicines Agency (AIFA). Low molecular weight heparins in the treatment of adult patients with COVID-19. Update: 24 November 2020. Available from: https://www.aifa.gov.it/documents/20142/1267737/Lowmolecular-weight- heparins_EN_24.11.2020.pdf/fc92d837e27a-17af-18db-9a8635fb19d5

15. Administrative Court of Region Lazio. Ruling n. 1557-2021. Available from: https://www.affaritaliani.it/static/upl2021/ 2021/0001/202101412_05.pdf

Received for publication: 8 April 2021. Accepted for publication: 9 April 2021.

This work is licensed under a Creative Commons Attribution-NonCommercial 4.0 International License (CC BY-NC 4.0).

CCopyright: the Author(s), 2021

Licensee PAGEPress, Italy

Multidisciplinary Respiratory Medicine 2021; $16: 768$

doi:10.4081/mrm.2021.768 